\title{
CRITICAL REFLECTION ON THE INTEGRATION OF HIV INTO THE HEALTH SCIENCE CURRICULUM
}

\author{
K. Smit* \\ e-mail: karlien.smit@nwu.ac.za
}

\section{M. Kruger*}

e-mail: lanthe.kruger@nwu.ac.za

\section{Greeff*}

e-mail: minrie.greef@nwu.ac.za

\section{A. Kruger*}

e-mail: annamarie.kruger@nwu.ac.za

*Africa Unit for Transdisciplinary Health Research (AUTHeR)

Faculty of Health Sciences

North-West University

Potchefstroom, South Africa

\section{ABSTRACT}

Health professionals need to have a multi-layered, nuanced understanding of HIV to become aware of the complexity of HIV and how it interacts with all aspects of life, ultimately affecting health and wellbeing. In this article, we critically reflect how we, as Health Sciences lecturers, took on the challenge to integrate HIV education into a multi-disciplinary module presented to secondyear health science students. These strategies included: (1) digital recordings on HIV and stigma, (2) HIV as 'a vehicle' to understand health-related concepts, and (3) a transdisciplinary health promotion project. We adopted a participatory, engaging pedagogy where students were encouraged to interact through critical discussion to develop critical thinking skills around their own attitudes regarding HIV and the impact on their professional practice. Through critically reflecting on their intersectionality of HIV with many aspects of health and wellbeing, we aimed to deepen students' understanding of HIV and the effect it has on the lives of their future patients.

Keywords: HIV, curriculum integration, higher education, health professionals, undergraduates, students

\section{INTRODUCTION}

The context of health is complex, dynamic and ever changing (WHO 2008). Health is defined by the WHO $(1948,100)$ as 'a state of complete physical, mental and social wellbeing and not merely the absence of disease or infirmity'. This definition has not changed for over 60 years, reflecting the shift in thinking from preventing illness and deaths resulting from infections and pests (Kruger 2012) towards a focus on health. The thought was that as countries develop, communicable diseases would cease to be the main source of ill-health (Omran 2005). 
However, more than 20 years after the first democratic election, South Africa is in the midst of a profound health transition, characterized by poor health status, especially among Black South Africans. South Africa remains one of the sub-Saharan countries with the highest incidence of Human Immunodeficiency Virus (HIV) in the world (WHO 2016; Chidrawi, Greeff, Temane and Ellis 2015; French, Greeff and Watson 2015). The high prevalence of HIV is further worsened by a combination of other poverty-related communicable diseases (e.g., tuberculosis); perinatal and maternal diseases/disorders, and violence-related injuries (Mayosi, Fisher, Lalloo, Sitas, Tollman and Bradshaw 2009; DEA 2013) including mother-to-child transmission and rape which have a direct bearing on HIV.

An estimated 0.8 per cent of adults (aged 15-49 years) worldwide are living with HIV, although the burden of the epidemic continues to vary considerably between countries and regions. Sub-Saharan Africa remains most severely affected, with nearly one in every 20 adults (4.9\%) living with HIV. This accounts for approximately 69 per cent of the people living with HIV worldwide (WHO 2016; UNAIDS 2014). The Black population is most severely affected (Horton 2004). Despite a decline (39\%) in AIDS-related deaths in sub-Saharan Africa between 2005 and 2013, this region still accounted for 74 per cent of all AIDS-related deaths in 2013. It is further estimated that there are 16 million women aged 15 years and older living with HIV; 80 per cent of them living in sub-Saharan Africa (UNAIDS 2014). Nearly 1.5 million new HIV infections and 1.1 AIDS-related deaths occurred in 2013 in sub-Sahara Africa alone (UNAIDS 2014).

The increase in prevalence of people living with HIV (PLWH) might be due to the antiretroviral treatment (ART) roll-out programs of governments (Samji, Cescon, Hogg, Modur, Althoff, Buchacz, Burchell, Cohen, Gebo, Gill et al. 2013). A decade ago, being diagnosed with HIV meant the likelihood of impending death. However, because of advances in medical science, HIV has become a chronic disease with which people can live longer if managed effectively (Deeks, Lewin and Havlir 2013). ART has been used in the West since the late 1990s but has only been rolled out in Africa systematically since 2002 (Peltzer and Ramlagan 2011) and only since 2007 in South Africa. Treatment was initially only available for those close to developing full blown AIDS, but more recently at an earlier stage of treatment (CD4 count of 500) (WHO 2015). This has changed the way HIV is perceived - from a death sentence to a chronic disease (Egger, Boulle, Schechter and Miotti 2005; Bekker, Venter, Cohen, Goemare, Van Custem, Boulle and Wood 2014). Therefore, treatment and care for a person with HIV should include a wide spectrum of disciplines and capabilities from these disciplines to ensure enhancement of holistic wellbeing (Holderness 2012). 
However, the holistic wellbeing of anyone living with (or affected by) HIV is threatened by stigma. HIV should therefore not only be perceived as a health issue but also as a social issue (HESA 2007). HIV at first presents itself as an aggressive virus which compromises the immune system and leads to sudden illness. This is a distinctive, sudden and extreme experience that not only affects the physical dimension of health, but also greatly affects social and psychological wellbeing, as well as that of family and the community they live in (French, Greeff, Watson and Doak 2014; French et al. 2015). Societies characterised by HIV also experience heightened stigma, discrimination, blame and collective denial (Parker and Aggleton 2003; Aggleton, Parker and Maluwa 2003; Wood and Rens 2014). According to Carr and Nyblade (2007), the accompanying stigma can be more challenging to cope with than the medical problems associated with HIV.

HIV stigmatisation also makes prevention a challenging task by forcing the epidemic underground and out of sight (Oanh, Ashburn, Pulerwitz, Ogden and Nyblade 2008; UNAIDS 2010). Stigma is most frequently defined as an 'attribute that is deeply discrediting' and that diminishes the carrier 'from a whole and usual person to a tainted, discounted one' (Goffman 1963, 3). According to Edward Edwin Cameron (2008, 1), HIV and AIDS 'is still a disease associated with a terrible stigma'. He further cautions that 'Stigma and accompanying discrimination are widely recognized as significant barriers to HIV prevention ...' . HIV stigma is experienced by the person living with HIV or AIDS (PLWH), the person living close to PLWH, the community, and even the health professionals working with PLWH (Chidrawi et al. 2015). However, it is also reported that health care professionals themselves are often the source of HIV associated stigma (Famoroti, Fernandes and Chima 2013). This forces us to take a new and focused look at the training of our future health professionals. They need to be informed and educated about personal and professional HIV prevention and support, and how to assist their patients who may experience HIV stigma or discrimination. This will allow them to embody practices that reduce HIV and HIV stigma (UN 2016).

The purpose of this article is to explain how the Faculty of Health Sciences at a South African university integrated HIV education into the curriculum of all second year health sciences students in a compulsory multidisciplinary health module. First we will discuss how HIV can be used to contribute to transformation of the curriculum in higher education, framing our argument within the transformative learning theory that underpinned the curriculum design. This will be followed by a short explanation of the methodology. We will give a summarised background and description of the compulsory multidisciplinary health module, where after our discussion will follow. We will conclude with recommendations on how HIV can be integrated 
into the curriculum based on our practical experience.

\section{HIV AND TRANSFORMATION IN HIGHER EDUCATION}

Higher education plays a significant role in the transformation of our wider society (Council on Higher Education 2013). According to the Council on Higher Education, universities must align with national developmental goals in order to be truly transformative in our education approaches. Curricula must be congruent with the knowledge, expertise and skills needs of a changing society (Badat 2010). For this reason and against the unique, yet complex, national health background, Higher Education South Africa (HESA 2007) proposed HIV integration into curriculum across all faculties. Using core modules is one of the most common ways of integrating HIV into the education of students (HESA 2007). In order to prepare students to function as health professionals within a complex world of health, higher education is faced with the challenge of adapting both curriculum content and pedagogy (Materu 2007) to help students to understand HIV from an intersectional perspective, so that they are able to empathise with the individuals and communities facing the multiple and complex adversities arising from the intersection of poverty, illness, stigmatisation and social norms.

Since students, particularly at our institution, tend to come from the more economically privileged sector of society, they are mostly unaware of the lived reality of the majority of the South African population. They tend to be resistant to the integration of HIV education, which has been described in literature as a form of 'AIDS fatigue' (Mitchell and Smith 2003), denial, fatalism, or a sense of invulnerability (Kelly 2001), and thus the '... pandemic is ... not regarded as of concern or interest to them' (Wood and Rens 2014, 66). The field of health includes a wide range of professionals, encompassing varying skills and expertise. Up to a few years ago, training was mainly mono-disciplinary in nature with a focus on illness within a structured environment of hospitals or clinic services. However, the primary health care approach has taken health professionals much closer to the people in their communities, requiring that health professionals possess certain competencies such as empathy and compassion for all, no matter their race, class or health status; to be able to work in a diverse society where vast inequalities exist; to be able to work in teams; and to have good interpersonal skills. Therefore, the health curriculum should take the above mentioned into account, be dynamic and should continuously adapt according to the needs of the ever-changing world of health (Materu 2007). Health professionals are challenged to emphasise health promotion through multi- and/or transdisciplinary team work by empowering individuals to take responsibility for their own health. The above demands change how health professionals are trained. They can no longer 
just be trained in silos focusing on their own discipline, but should be exposed to multi- and transdisciplinary approaches to health involving all people across the life span and in all aspects of health (Kruger 2012).

By integrating HIV education into the curriculum of future health professionals, following a more 'holistic, critical and self-reflective approach’ (Wood 2011), it could have a threefold purpose. Firstly, these students themselves need to be educated about HIV, to reduce their own vulnerability. Secondly, they need to be prepared to become HIV-competent health professionals who know how to ethically manage HIV in whatever profession they will find themselves. Lastly, they need to be shaped into a strong new generation of professionals (Gold 2016), able to educate others to appreciate the intersectionality of HIV to enable them to find more contextually and culturally relevant approaches to treatment, prevention and health promotion. They should not only be able to manage HIV from a clinical perspective, but should also be able to respond to the needs of HIV positive individuals, reduce HIV stigma within the profession and communities as well as influence those within their respective environments to develop empathy and respect for all, no matter their circumstances. We need to train compassionate, HIV-competent health professionals. This led us to ask the following question:

- How can health sciences students be prepared for the complex world of health and become HIV competent health professionals?

\section{THEORETICAL FRAMEWORK}

Transformative Learning Theory (a 10-phase model of perspective transformation) was first introduced by Mezirow in 1978 (Mezirow 1997) and describes how one learns and why one learns (Kitchenham 2008). Mezirow $(1997,5)$ defined Transformative Learning Theory as 'the process of affecting change in a frame of reference' and when applied in education, can take on either an objective or a subjective form of reframing. Transformative learning requires learners to be critical of their own assumptions and to incorporate new information into already welldeveloped frames of reference. Transformative Learning Theory therefore refers to 'a deep, structural shift in basic premises of thought, feelings, and actions' (Transformative Learning Centre 2004, 1). Learning thus takes places through critical self-reflection of their epistemological and ontological assumptions (Kitchenham 2008). The specific teaching and learning strategies utilised in this module are based on transformative learning theory and include problem-based learning (by means of case studies) and elements of project-based learning (by means of transdisciplinary health promotion projects) (Mezirow 1997). 


\section{BACKGROUND AND DESCRIPTION OF THE COMPULSORY MULTIDISCIPLINARY HEALTH MODULE}

In 2009, the Faculty of Health Sciences at a tertiary institution within South Africa developed a compulsory multidisciplinary health module for all undergraduate second year students. The original module was designed to facilitate the student to develop a critical mind-set with regard to understanding the world. The Faculty of Health Sciences made it more specific for the various health professions by developing it into a module that would help students to understand the world of health. It included various worldviews and ideologies to be presented by lecturers from the School of Philosophy, as well as various concepts and approaches found in the field of health to be presented by health professionals from various disciplines. The rationale behind the module was: (1) to give students the opportunity to understand their own worldview and the way in which it influences them as a health professional; (2) to expose students to fellow students from all the different subject disciplines within the Faculty of Health Sciences in order to lay the foundation for their successful multi- and transdisciplinary team work in future; and (3) to develop them as future health professionals who can take the lead in the design and implementation of health promoting community interventions. The relevance and importance of this approach lies in the interrelated understanding between different disciplines, integrated into a holistic approach to health from different perspectives. Students and facilitators from different disciplines/scientific fields are able to transcend conceptual, theoretical and methodological frameworks and to share their ideas and results across disciplinary silos to affect relevant community intervention and participation.

At the same time, this tertiary institution adopted a campus-wide pro-active approach to HIV education in an attempt to prevent ignorance and misinformation with regard to HIV amongst students. A course on 'Mainstreaming HIV into the curriculum of undergraduate students' was presented to key stakeholders in the academic fraternity by an external facilitator. The aim of this course was to ensure that a percentage of time was allocated to HIV education in appropriate modules. The Faculty of Health Sciences decided to focus on HIV stigma and to integrate it into the mentioned module. A virtual digital disc on HIV and HIV stigma was produced and focused on three aspects: (1) a lecture on understanding HIV stigma; (2) people living with HIV (PLWH) telling their personal stories of HIV stigma; and (3) having students reflect on how their views of HIV and PLWH impact on how they handle PLWH. The Faculty of Health Sciences used a pro-active approach to HIV education, and integrated HIV stigma reduction into this multidisciplinary health module in an attempt to target all the students of the 
Faculty of Health Sciences.

In 2010, this compulsory multidisciplinary health module ('Know and understand the world of health' - WVGW 221) was implemented in all programmes within the Faculty of Health Sciences across three campuses. The module is a second year, second semester module. The authors of this article have been involved in either the development or adaptation of the module or have taught it for at least one semester. This module is a 12 credit module, implying that students must spend a total of 120 hours to master the set module outcomes successfully. Figure 1 provides an overview of the module at the end of 2014, according to the module documents. Although the outcomes of the module do not specifically mention HIV, it is interwoven into all the study units and was not presented as an isolated theme as shown in Figure 2. The reason why we chose to interweave HIV and not to introduce it as isolated theme was an attempt to avoid 'Aids fatigue' in students.

Since the implementation of this module in 2010, lecturers have critically reflected after each semester to improve the module for the following year. Over the five-year period (2010 to 2014), the module was therefore adapted annually in order to establish best teaching and learning practice and to ensure that the students achieve the set module outcomes.

\section{How was HIV integrated into the compulsory multidisciplinary health module?}

During the development of this module, we grappled with the question of how to successfully integrate HIV into the curriculum, considering the resistance and general apathy towards HIV education we assumed we would face from students. Inspired to come up with a new and innovative approach to HIV integration, we decided to focus less on understanding HIV as a physical disease, but rather on HIV stigma reduction among students to make them more empathic health professionals who could actively work towards reducing HIV-related stigma. Figure 2 provides a visual illustration of how HIV education was integrated and adapted over time within this compulsory multidisciplinary health module.

Different strategies to integrate HIV into the multidisciplinary health module were implemented from 2010 to 2014. These strategies included: (1) digital recordings on HIV and stigma; (2) HIV as 'a vehicle' to understand health-related concepts; and (3) a transdisciplinary health promotion project. In the section below we will discuss how these strategies were implemented, critically reflected on and adapted accordingly over time. Within all of these strategies it is important to realise that before each face-to-face contact session the students were expected to do preparatory work and write a preparatory test on theoretical concepts. During their preparatory work students were guided by the interactive e-guide to answer critical 
questions regarding the work. During the face-to-face contact sessions, the lecturers explained theoretical concepts to students and provided students with opportunities to critically discuss their answers to these critical questions. Case studies and a transdisciplinary health promotion project were also used to stimulate critical thinking skills.

\section{Strategy 1: Digital recordings on HIV and stigma}

In 2010 and 2011, a Digital Voice Recording (DVD) focussing on several aspects of HIV stigma reduction was included as part of students' study material. It was expected of students to view the recording in their own time and then critically discuss their views on HIV and stigma in class. However, we soon learnt that students were not viewing these recordings. During the class discussions, a great deal of denial and ignorance of HIV and high levels of resistance from students was observed by lecturers. According to student verbal feedback in class, reasons for this included that students felt: 1) overwhelmed by HIV education; 2) they thought they knew all there is to know about HIV; and 3) they did not think they were at risk of contracting HIV; therefore, it was not of importance to them.

During the annual feedback discussions of lecturers regarding improving the module we realised that students needed to be motivated and almost 'forced' to actually view the recordings, indicating that a different approach for the above mentioned strategy was needed. We decided to try and motivate the students to view the recordings by introducing this as part of a preparatory test in 2012. The HIV stigma recordings were incorporated into one of several preparatory tests the students were expected to complete electronically, within the University's electronic platform (eFundi), before specific class sessions. The total participation mark students could obtain by doing their preparatory tests was 10 per cent. Several students found this method to be good enough motivation to actually view these recordings, but we still observed and experienced resistance from some students as they felt that the recordings are too long and they did not want to spend the needed amount of time to view it. We realised that when we present information to students, it must be in short sound bites instead of a long video. In future, we will make use of shorter video clips or integrate stigma into a case study and combine it with other health concepts, for example, health ethics.

\section{Strategy 2: HIV as a 'vehicle' to understand health-related concepts}

Due to the complexity and intersectionality of HIV, it is a good topic for enabling critical 


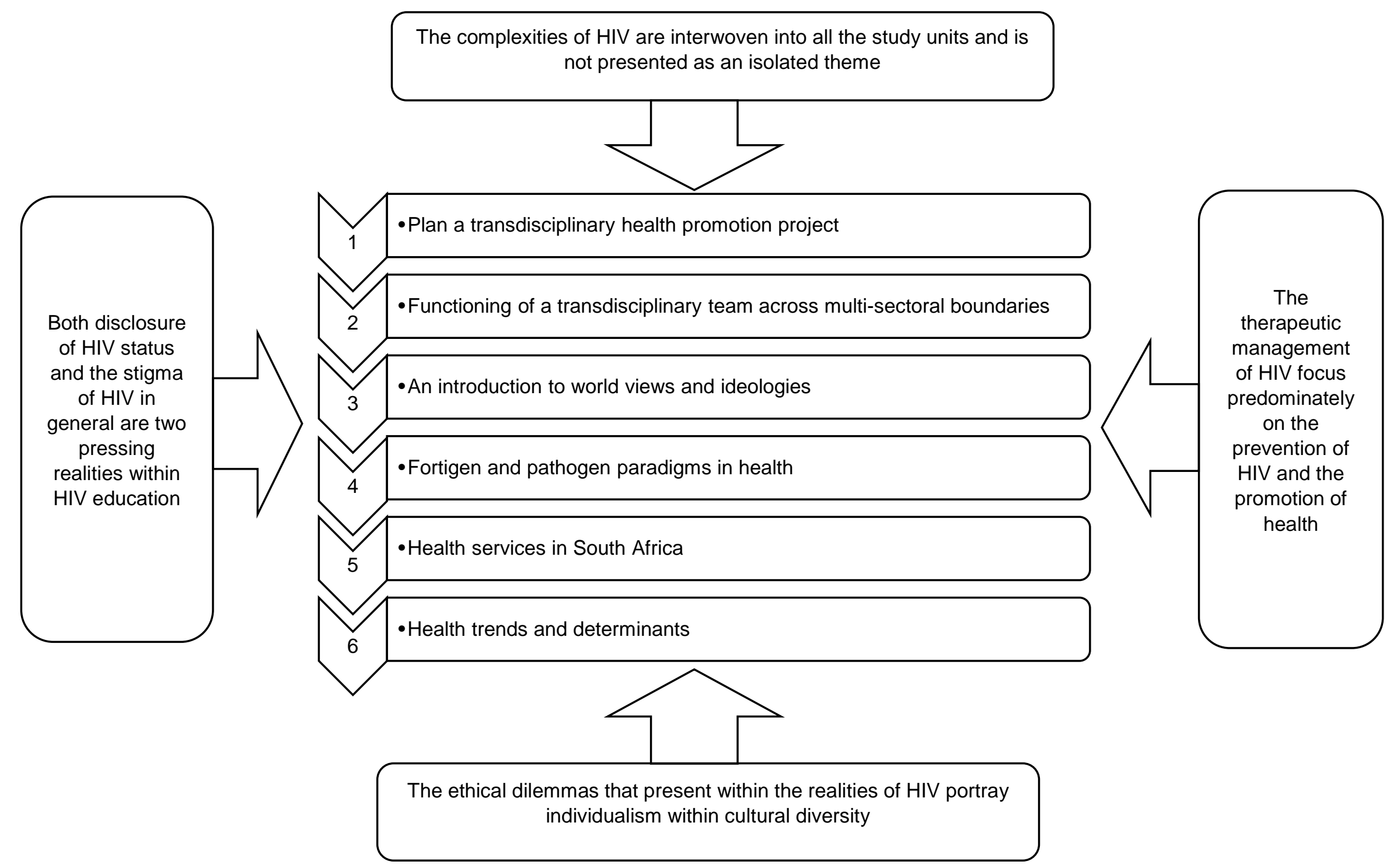

Figure 1: An overview of the module at the end of 2014, according to the module documents 


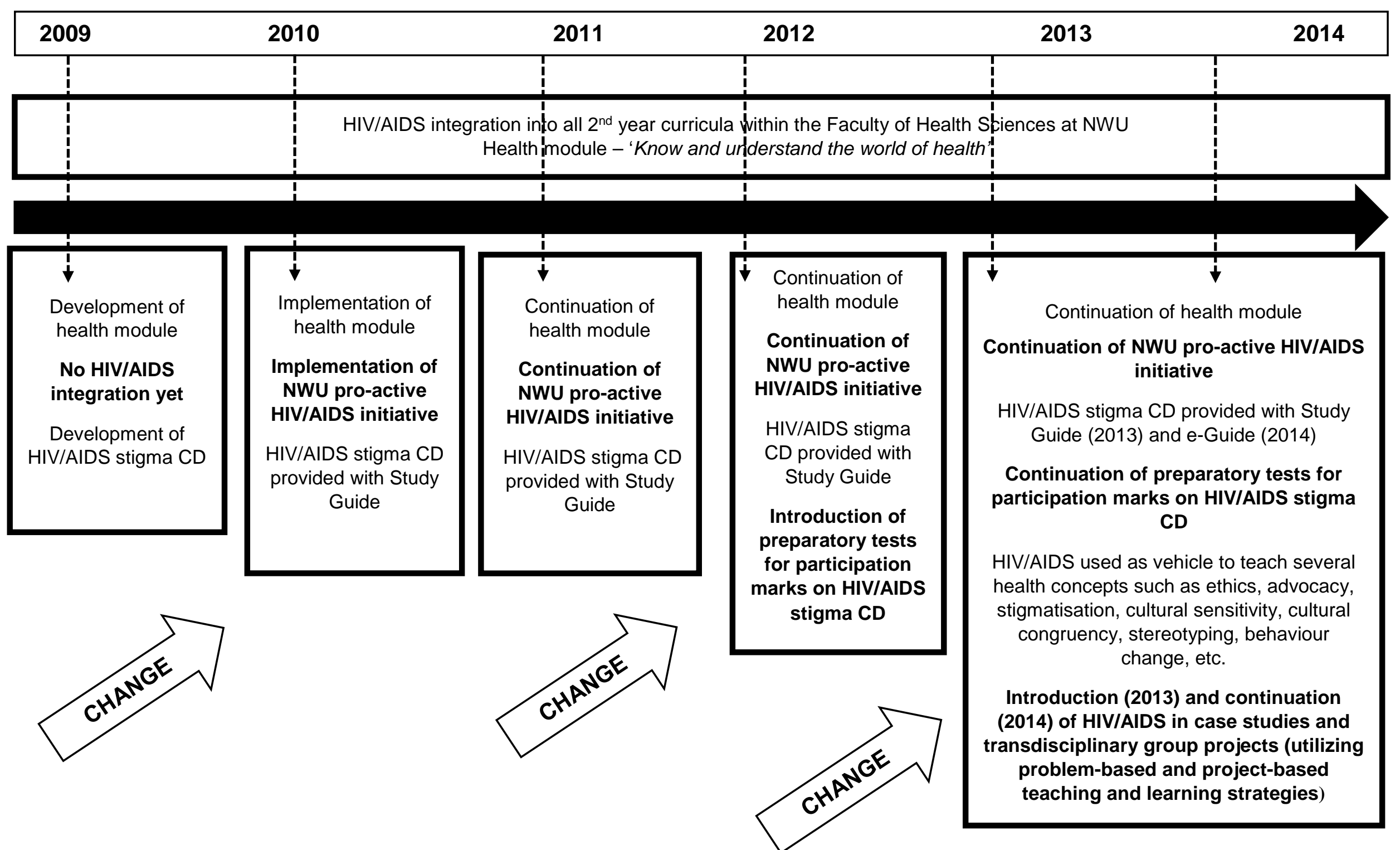

Figure 2: Visual illustration of how HIVIAIDS education was integrated into the module 'know and understand the world of health' 
discussions regarding ethical dilemmas that demonstrate the complex world of health. We observed in our classes that students were more approachable and responsive in terms of discussions around HIV, when HIV was utilised as a 'vehicle' to understanding a health-related concept. Critical reflection allowed us to build on this strategy. During 2013 and 2014, we therefore used HIV (together with other communicable and non-communicable diseases such as hypertension, diabetes mellitus, obesity, etc.) to educate students on the different health concepts that they need to master within this module in order to develop as compassionate and competent health professionals.

Advocacy was introduced by means of an HIV case study. This case study introduces HIV as a multi-dimensional issue that not only impacts on all aspects of the life of the individual, but also on the people in their personal and professional network. Students were taught when and why advocacy is needed, and how to advocate for an individual and/or community as compassionate and competent health professionals. This was evaluated by means of a case study assignment which students needed to complete within their individual portfolios. We found that students did not perceive HIV as only a physical disease, but also recognised that HIV implicates social and physiological dimensions of health that implicates not only on the individual, but also on the family and the community. Students also acknowledge HIV stigma.

World views were another concept explored by means of this strategy. HIV posters were utilised within this health module in order to teach students the different world views they might come across. In-depth class discussions were held where lecturers and students debated the different world views that the HIV posters represent. Figure 3 presents an example of two of these posters (Brown and Beck 2009). The rationale behind using HIV posters was an attempt to demonstrate to students how the lens through which they view the world (i.e., their world views) plays an integral role within the world of health; especially regarding diseases that students and lecturers find difficult to talk about such as HIV.

Furthermore, HIV was also used as a vehicle to educate students on concepts such as stigmatisation, cultural sensitivity, cultural congruency, stereotyping and behaviour change. Because of the complexity of HIV as a multi-dimensional disease, it is possible to interweave it as an example within case studies to confront students with various dilemmas and teach them different health-related concepts. An example of this is where we utilised HIV as a topic for explaining the Health Belief Model for behaviour change to students. Students were introduced to the Health Belief Model which is based on specific core assumptions and statements. A person will take health-related actions if he or she (i) feels that a negative state of health (for 
instance, HIV infection) can be avoided; (ii) has a positive expectation that if he or she takes the recommended steps (for example, use of a condom) the negative state of health will be avoided; and (iii) believes that he or she was successful owing to his or her having followed the proposed health steps (for example, the use of a condom will prevent the transfer of HIV). Thereafter students were involved in a critical discussion around the four components of the Health Belief Model that represents the perceived threats or total advantages. These include: (1) perceived susceptibility (a person's opinion with regard to the possibility that he or she will contract the disease); (2) perceived severity (a person's opinion with regard to the severity of the disease/illness and the consequences thereof); (3) perceived benefits (a person's belief in the effectiveness of the recommended action to decrease the risk of major impact); and (4) perceived barriers (a person's opinion of the tangible and psychological advantages of the recommended action). During this discussion, we also problematized the applicability of this model to behaviour change in contexts where the individual's behaviour and agency is constrained by social and cultural norms, meaning that change is not likely to happen unless these norms are also questioned.

\section{Strategy 3: A transdisciplinary health promotion project}

We also integrated HIV as part of the identified health problem students were expected to address by means of a compulsory transdisciplinary group project. Within this module, students were expected to address a given health problem within a specific scenario in transdisciplinary groups of approximately 20 students. The aim of these theoretical group projects was to prepare the students as future health professionals for the complex world of health through following a transdisciplinary approach to health promotion. Students were tasked to take into account the high burden that HIV poses on South African communities when they plan their transdisciplinary health promotion projects. Once again, the complexity which HIV poses, in combination with other communicable or non-communicable diseases, created a realistic learning opportunity for the students in their preparation to become responsible citizens and ethical health professionals. We observed that students found this unique approach to problem solving strange and challenging, but that it assisted them in their learning process. Students had the opportunity to critically reflect on their perceptions regarding the transdisciplinary health promotion projects. We observed that students in general realised the complexity of the world of health and that complex health problems such as HIV cannot be solved in isolation, but require the perspectives of different disciplines. 

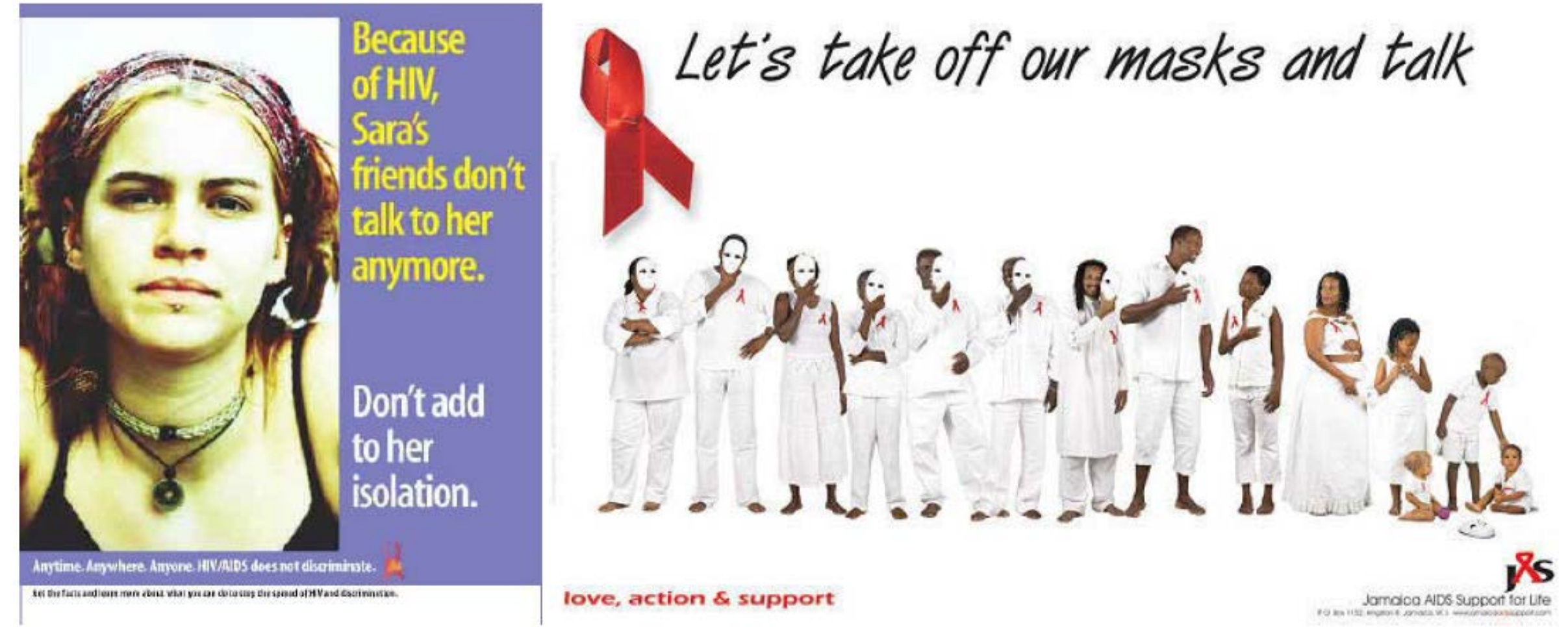

Figure 3: Example of posters that may appeal to the green worldview about HIVIAIDS with reference to inclusion, stigma, and discrimination of people living with HIVIAIDS (Brown and Beck 2009) 


\section{CONCLUSION}

Within this module the approaches that were adopted to integrate HIV stigma included a focus on stigma reduction, using HIV as a 'vehicle' to explain health-related concepts and as an example for a problem solving approach through case studies. Over time, as the module developed through annual critical reflection, we adopted a more participatory and engaging pedagogy where students were encouraged to interact through critical discussion in order to develop critical thinking skills around their own attitudes regarding HIV and how it impacts on their own stigmatization and their professional practice. Students are shaped into ethical professionals through critical discussions regarding health ethics and human rights as portrayed in the Patients Right's Charter (DoH 1996). The ethical dilemmas students are exposed to during these discussions provide them with the opportunity to express their individual opinions, framed within their own world views, within a culturally diverse group of peers. This all takes place against the backdrop of complex HIV health-related realities. By providing students with the opportunity to critically reflect on world views and ideologies, taking into account the complexity HIV poses, they are guided towards adopting a more inclusive and empathic ontology. When HIV stigma is utilised as a 'vehicle' for teaching students several health concepts, students are made aware of how HIV stigma is adding to the complexity of health. All of these graduate attributes that students gain from this module would hopefully aid them in becoming responsible HIV-competent health professionals. In order for us to determine whether the strategies we implemented have the impact we intended, further evaluation research is needed. We trust that the pedagogical strategies we have shared in this article will be of use to other educators of health professionals and that they will in turn use them to help transform the curriculum of health science programmes to raise student awareness of the need to adopt an intersectional and empathic understanding of HIV and its implications for the lives of their future patients.

\section{REFERENCES}

Aggleton, P., R. Parker and M. Maluwa. 2003. Stigma, discrimination and HIV/AIDS in Latin America and the Carribean. Sustainable Development Department technical paper series. Washington, DC: Inter-American Development Bank. http://www.iadb.org/wmsfiles/products/publications/ documents/354523.pdf (accessed 2 March 2016).

Badat, S. 2010. The challenges of transformation in higher education and training institutions in South Africa. Development Bank of South Africa report. http://www.dbsa.org/EN/AboutUs/Publications/Documents/The\%20challenges\%20of\%20transformation\%20in\%20higher\%20e ducation\%20and\%20training\%20institutions\%20in\%20South\%20Africa\%20by\%20Saleem\%20 Badat.pdf (accessed 2 March 2016).

Bekker, L. G., F. Venter, K. Cohen, E. Goemare, E. Van Custem, A. Boulle and R. Wood. 2014. 
Provision of antiretroviral therapy in South Africa: The nuts and bolts. Antiretroviral Therapy 19(3): 105-116.

Brown, B. C. and D. E. Beck. 2009. How to tailor public communications about hiv/aids to different worldviews. http://debategraph.org/Handler.ashx?path=ROOT\%2Fu13592\%2FBarrett+Brown_ Don+Beck_Communicating+About+HIV-AIDS+to+Different+Worldviews.pdf (accessed $1 \overline{7}$ March 2016).

Cameron, E. J. B. 2008. Justice Edwin Cameron adds a new dimension to China-Africa relations. UNAIDS/Zhou Dao. http://www.unaids.org/en/resources/presscentre/featurestories/2008/october /20081031justicecameron (accessed 7 May 2012).

Carr, D. and L. Nyblade. 2007. Taking action against HIV stigma and discrimination. Guidance document and supporting resources. London: Department for International Development. http://www.icrw.org/sites/default/files/publications/DFID-Taking-Action-Against-HIV-Stigmaand-Discrimination.pdf (accessed 2 March 2016).

Chidrawi, H. C., M. Greeff, M. Temane and S. Ellis. 2015. Changeover-time in psychosocial wellbeing of people living with HIV and people living close to them after an HIV stigma reduction and wellness enhancement community intervention. African Journal of AIDS Research 14(1): 1-12.

Council on Higher Education. 2013. A Proposal for undergraduate curriculum reform in South Africa: The case for a flexible curriculum structure. Report of the task team on undergraduate curriculum structure.http://www.che.ac.za/sites/default/files/publications/Full_Report.pdf (accessed 2 March 2016).

DEA see Department of Environmental Affairs.

Department of Environmental Affairs. 2013. Long-term adaptation scenarios flagship research programme (LTAS) for South Africa. Summary for policy makers. http://www.sanbi.org/ sites/default/files/documents/documents/ltassummary-policy-makers2013 high-res.pdf (accessed 17 March 2016).

Deeks, S. G., S. R. Lewin and D. V. Havlir. 2013. The end of AIDS: HIV infection as a chronic disease. Lancet 382(9903): 1525-1533.

Department of Health. 1996. The patients' rights charter. http://www.justice.gov.za/VC/docs/ policy/Patient\%20Rights\%20Charter.pdf (accessed 4 April 2012).

DoH see Department of Health.

Egger, M., A. Boulle, M. Schechter and P. Miotti. 2005. Antiretroviral therapy in resource-poor settings: Scaling up inequalities? International Journal of Epidemiology 34(3): 509-512.

Famoroti, T. O., L. Fernandes and S. C. Chima. 2013. Stigmatization of people living with HIV/AIDS by healthcare workers at a tertiary hospital in KwaZulu-Natal, South Africa: A cross-sectional descriptive study. BMC Medical Ethics 14(1): 1-10.

French, H., M. Greeff, M. J. Watson and M. Doak. 2014. A comprehensive HIV stigma-reduction and wellness-enhancement community intervention: A case study. Journal of the Association of Nurses in AIDS Care 26(1): 81-96.

French, H., M. Greeff and M. J. Watson. 2015. Experiences of people living with HIV and people living close to them of a comprehensive HIV stigma reduction community intervention in an urban and rural setting. AIDS Care 27(8): 1042-1046.

Goffman, E. 1963. Stigma: Notes on the management of spoilt identity. Englewood Cliffs, NJ: Prentice Hall.

Gold, J. P. 2016. The ten pillars shaping the future of health science education: External forces, ongoing evolution and future trends. The education \& training for health care transformation conference. https://www.nationalahec.org/pdfs/TheFutureofHealthSciencesEducation-External ForcesOngoingEvolution.pdf (accessed 1 March 2016).

HESA see Higher Education South Africa.

Higher Education South Africa. 2007. Case studies in mainstreaming: Integrating HIV and AIDS 
realities into South African higher education curricula. Pretoria. http://www.wsu.ac.za/ cha/publications/Curriculum\%20Integration\%20Book\%20TEXT.pdf (accessed 2 March 2016).

Holderness, W. L. 2012. Equiping educators to address HIV and AIDS: A review of selected teacher education initiatives. Journal of Social Aspects of HIV/AIDS 9: 48-55.

Horton, M. 2004. HIV/AIDS in South Africa. In Post-apartheid South Africa: The first ten years, ed. M. Nowak and L. A. Ricci, 113-129. Washington, DC: International Monetary Fund.

Kelly, M. J. 2001. Challenging the challenger understanding and expanding the response of universities in Africa to HIV/AIDS. A synthesis report for the Working Group on Higher Education (WGHE) and the Association for the Development of Education in Africa (ADEA). Washington, DC: ADEA Working Group on Higher Education. http://hivhealthclearinghouse. unesco.org/sites/default/files/resources/ADEA\%20Kelly\%20Challenging\%20the\%20Challenger. pdf (accessed 2 March 2016).

Kitchenham, A. 2008. The evolution of John Mezirow's transformative learning theory. Journal of Transformative Education 6(2): 104-123.

Kruger, A. 2012. Public health: A paradigm shift. Scientific contributions, Series H: Inaugural address $n r$. 256. Potchefstroom, South Africa: North-West University. http://dspace.nwu.ac.za/ bitstream/handle/10394/8565/Kruger_A.pdf?sequence=1 (accessed 1 March 2016).

Materu, P. 2007. Higher education quality assurance in Sub-Saharan Africa. Status, challenges, opportunities, and promising practices. World Bank working paper no. 124. Washington, DC: The World Bank. http://www.eua.be/Libraries/qa-connect/wp124_qa_higher_edu_ africa.pdf?sfvrsn=0 (accessed 2 March 2016).

Mayosi, B. M., A. J. Flisher, U. G. Lalloo, F. Sitas, S. M. Tollman and D. Bradshaw. 2009. The burden of non-communicable diseases in South Africa. Lancet 374: 934-947.

Mezirow, J. 1997. Transformative learning: Theory and practice. New Directions for Adult and Continuing Education 74: 5-12.

Mitchell, C. and A. Smith. 2003. 'Sick of AIDS': Life, literacy and South African youth. Culture, Health \& Sexuality 5(6): 513-522.

Oanh, K. T. H., K. Ashburn, J. Pulerwitz, J. Ogden and L. Nyblade. 2008. Improving hospital-based quality of care in Vietnam by reducing HIV-related stigma and discrimination. Horizons Final Report. Washington, DC. The Population Council Inc. http://www.icrw.org/files/ publications/Improving-hospital-based-quality-of-care-in-Vietnam-by-reducing-HIV-relatedstigma-and-discrimination.pdf (accessed 2 March 2016).

Omran, A. R. 2005. The epidemiologic transition: A theory of the epidemiology of population change. Milbank Quarterly 83(4): 731-757.

Parker, R. and P. Aggleton. 2003. HIV and AIDS-related stigma and discrimination: A conceptual framework and implications for action. Social Sciences \& Medicine 57: 13-24.

Peltzer, K. and S. Ramlagan. 2011. Perceived stigma among patients receiving antiretroviral therapy: A prospective study in KwaZulu-Natal, South Africa. AIDS Care 23(1): 60-68.

Samji, H., A. Cescon, R. S. Hogg, S. P. Modur, K. N. Althoff, K. Buchacz, A. N. Burchell, M. Cohen, K. A. Gebo, M. J. Gill, A. Justice, G. Kirk, M. B. Klein, P. T. Korthuis, J. Martin, S. Napravnik, S. B. Rourke, T. R. Sterling, M. J. Silverberg, S. Deeks, L. P. Jacobson, R. J. Bosch, M. M. Kitahata, J. J. Goedert, R. Moore and S. J. Gange. 2013. Closing the gap: Increases in life expectancy among treated HIV-positive individuals in the United States and Canada. PLOS ONE 8(12): $1-8$.

Transformative Learning Centre. 2004. The TLC approach to transformative learning: Grounded hope. Toronto, Canada: University of Toronto. http://legacy.oise.utoronto.ca/research/ tlcentre/about.html (accessed 12 April 2016).

United Nations. 2016. Millennium development goals and beyond 2015. Goal 6: Combat hiv/aids, malaria and other diseases. http://www.un.org/millenniumgoals/aids.shtml (accessed 12 April 2016). 


\section{UN see United Nations.}

United Nations Programme on HIV/AIDS. 2010. UNAIDS report on the global AIDS epidemic. Global report. Geneva. http://www.unaids.org/globalreport/documents/20101123_GlobalReport_ full_en.pdf (accessed 12 November 2012).

United Nations Programme on HIV/AIDS. 2014. The gap report. Geneva. http://www.unaids.org/ sites/default/files/en/media/unaids/contentassets/documents/unaidspublication/2014/UNAIDS_G ap_report_en.pdf (accessed 16 March 2016).

Wood, L. 2011. HIV and AIDS education in pre-service teacher programmes: Lessons learned from experience in a Post-Graduate Certificate in Education. Acta Academica 43(4): 181-202.

Wood, L. and J. Rens. 2014. Treating 'AIDS blindness': A critical pedagogical approach to HIV education at tertiary level. African Journal of AIDS Research 13: 65-73.

World Health Organization. 1948. Preamble to the Constitution of the World Health Organization as adopted by the International Health Conference, New York, 19-22 June 1946; signed on 22 July 1946 by the representatives of 61 States (Official Records of the World Health Organization, no. 2, p. 100) and entered into force on 7 April 1948. http://www.who.int/about/definition/ en/print.html (accessed 17 March 2016).

World Health Organisation. 2015. Guideline on when to start antiretroviral therapy and on preexposure prophylaxis for HIV, 78. Geneva. http://apps.who.int/iris/bitstream/10665/ 186275/1/9789241509565_eng.pdf (accessed 16 March 2016).

World Health Organization. 2016. Global health observatory (GHO) data. http://www.who.int/ gho/hiv/en/ (accessed 1 June 2015). 